\title{
INSTITUTIONAL RESPONSES TO INCREASED EXTERNAL SUPPORT FOR GRADUATE STUDENTS
}

\author{
Ronald G. Ehrenberg, Daniel I. Rees, and Dominic J. Brewer*
}

\begin{abstract}
This paper uses institutionally based data to estimate how universities would respond to increased federal support for graduate students. It demonstrates that doctorate-producing universities do respond to changes in the number of full-time science and engineering students supported on external funds by altering the number of students that they support on institutional funds. Institutional adjustment to changes in external support levels appears to be quite rapid. However, in the aggregate, the magnitude of these responses is quite small.
\end{abstract}

\section{Introduction}

$\mathbf{P}$ ROJECTIONS of forthcoming shortages of Ph.D.s, and thus new faculty for the academic sector, abound. ${ }^{1}$ Indeed, one major book projected at least a 43 percent underproduction of new doctorates in the arts and sciences as a whole during the 1997-2002 period. ${ }^{2}$ Part of the reason for these projections is that American college graduates are much less likely to receive doctorates today than they were 20 years ago. While the ratio of doctorates granted by American universities to bachelors' degrees granted by American colleges and universities six years earlier was 0.064 in $1970-71$, it fell to 0.035 in 1978-79 and has remained roughly constant at the lower level since then. ${ }^{3}$

Numerous factors probably contribute to the decline in the propensity of American college graduates to receive doctorates, including the weak academic labor market that existed

Received for publication February 13, 1992. Revision accepted for publication December 21, 1992.

${ }^{*}$ Cornell University and the National Bureau of Economic Research; University of Colorado, Denver; and the Rand Corporation, respectively.

We are grateful to Alan Fechter at the National Research Council for encouraging us to undertake this study, and to Cornell University, the NBER and the National Science Foundation for research support. An earlier paper, Ehrenberg, Rees and Brewer (1992) presents preliminary analyses using fewer years' data and fewer models. We are also grateful to Michael McPherson and numerous colleagues at Cornell and the NBER, we well as to two referees and the editor, for their comments. The views expressed are solely our own and do not necessarily reflect the views of any of the abovementioned institutions or individuals.

${ }^{1}$ See, for example, Bowen and Sosa (1989).

2 Bowen and Sosa, table 8.5. For a less pessimistic view, see Ehrenberg (1991).

${ }^{3}$ Ehrenberg (1991), table 6.4 . throughout the period. Between academic years 1970-71 and 1980-81 the salary of the average faculty member in the United States fell by about $21.1 \%$ in real terms. While faculty salaries rose in real terms during the $1980 \mathrm{~s}$, by the end of the decade, the average faculty member was barely earning in real terms what he or she had earned twenty years earlier. ${ }^{4}$

Another important factor may well be the increase in the length of time necessary for doctorate students to complete their programs. The median registered time to degree for new Ph.D.s granted in the United States in 1968 was 5.5 years. By 1988, this figure had risen to 6.9 years. The increase has been even more dramatic in some fields; for example, in the social sciences median registered time to degree rose from 5.1 to 7.4 years and in the humanities from 5.5 to 8.5 years during the same period. ${ }^{5}$ Increases in times-to-degree may also have been at least partially due to the weak academic labor market that prevailed during the period. ${ }^{6}$

Economists define shortages as arising when, at the prevailing salaries in an occupation, the quantity of labor demanded exceeds the quantity of labor supplied. As long as salaries are free to rise, shortages will eventually be eliminated. Concern over potential shortages of doctorates to academia occurs both because academic institutions may not possess the resources to increase faculty salaries substantially and because the time it takes graduate students to complete doctoral degrees is sufficiently long that even if salaries were to rise, the supply of new doctorates would not increase for a number of years. Thus, if shortages do materialize in the future, they may persist for a number of years.

\footnotetext{
${ }^{4}$ See Ehrenberg (1992).

${ }^{5}$ National Research Council (1989), table I. Bowen, Lord and Sosa (1991) have shown that part of the reported increase in times-to-degree in the humanities is a statistical artifact caused by the grouping of individuals by year of degree, rather than by year of program entrance, during a period in which the size of entering cohorts was decreasing.

${ }^{6}$ See Breneman (1976).
} 
Among the policies urged to prevent future Ph.D. shortages is increased federal support for graduate students. Such a policy would reduce the private costs of doctoral study and thus hopefully should increase the number of college graduates willing to undertake graduate study. To the extent that financial support reduces the time students need to complete degrees and increases their probability of completing doctoral programs, the future supply of Ph.D.s should further increase. While conceptually these roles of financial support on the supply of doctorates are clear, empirical evidence on the effects of financial support on doctoral production is actually quite scanty. $^{7}$

Lost in the policy debate, however, has been any concern for the possibility that changes in federal support, or other external support to the institution, for graduate education may simply induce an academic institution to redirect its own financial resources in a way that at least partially frustrates the intent of such a policy. For example, increased federal support for graduate students in the sciences may lead an institution to cut back somewhat on (or not increase as rapidly as it had planned) its own internal support for graduate students in the sciences and use the funds saved either to support graduate students in other disciplines or for other purposes (e.g., nongraduate student expenditures or moderating planned tuition increases). Conversely, faced with cutbacks in federal or other external support, institutions may react by attempting to partially offset the cutbacks by increasing their own internal support for graduate education.

To the extent that changes in external financial support for graduate education lead institutions to alter their own support levels, or allocations across fields, the changes in the field composition and total number of doctorate students supported that result may be different than policymakers intended. To fully analyze the likely effects of an increase in federal support for graduate students, an analysis of the extent to which the federal funds would displace institutional funds is thus required. Such an analysis is undertaken in this paper, using institutionally-based data for science (including social science) and engineering fields. Unfortunately, data do not exist that would per-

\footnotetext{
${ }^{7}$ See Ehrenberg, chapter 8.
}

mit similar analyses for the humanities and for professional fields other than engineering.

We begin in the next section with a discussion of the aggregate time-series evidence on how support for graduate students in science and engineering has changed. While this evidence suggests that federal policies may influence institutional support levels, causation can not be inferred from these aggregate data.

In section III, we present institutionally-based econometric analyses of the determinants of the number of full-time graduate students in science and engineering fields that receive institutional support. The analyses are extended in section IV to field-specific data and attempts made to ascertain if increased external support to one field may influence internal support allocations to other fields. The brief concluding section summarizes our findings and lays out an agenda for future research.

\section{Aggregate Time-Series Evidence}

Data for the 1966 to 1988 period on the number of full-time science (including the social sciences and psychology) and engineering graduate students (FTSEG) in doctorate-granting institutions, and the number of these by major source of support, come from the National Science Foundation. The percentages of FTSEG by major source of support each year are presented in table 1.

The data in columns (A) come from a survey whose scope changed over time. For example, in 1972 the survey was expanded to include graduate students in doctorate-granting institutions in departments that granted only masters degrees, while in 1973 it was expanded to include graduate students in medical and clinical sciences. Response rates to this survey varied over time. The data in columns (B) come from a separate, but similar survey. Response rates to this latter survey also varied over time. The two surveys overlapped during the 1974 to 1977 period and for the last three years in which they overlapped, they yielded virtually identical aggregate numbers.

During the 1966 to 1988 period, the number of FTSEG at doctorate-granting institutions whose major source of support came from the federal government fluctuated in the 43,000 to almost 55,000 range. In recent years, however, there has 
INSTITUTIONAL RESPONSES TO INCREASED EXTERNAL FUNDS

\begin{tabular}{|c|c|c|c|c|c|c|c|c|}
\hline \multirow[b]{2}{*}{ Year } & \multicolumn{2}{|c|}{$\begin{array}{l}\text { Percent } \\
\text { Federal }\end{array}$} & \multicolumn{2}{|c|}{$\begin{array}{c}\text { Percent } \\
\text { Institutional }\end{array}$} & \multicolumn{2}{|c|}{$\begin{array}{l}\text { Percent Other } \\
\text { Outside Support }\end{array}$} & \multicolumn{2}{|c|}{$\begin{array}{c}\text { Percent } \\
\text { Self-Support }\end{array}$} \\
\hline & (A) & (B) & (A) & (B) & (A) & (B) & $\overline{(\mathrm{A})}$ & (B) \\
\hline 1966 & 40.9 & & 35.0 & & 6.1 & & 18.0 & \\
\hline 1969 & 36.6 & & 35.7 & & 9.0 & & 18.6 & \\
\hline 1970 & 34.4 & & 36.9 & & 9.2 & & 19.5 & \\
\hline 1971 & 31.7 & & 37.0 & & 8.8 & & 22.4 & \\
\hline 1972 & 30.0 & & 38.6 & & 8.3 & & 23.1 & \\
\hline 1974 & 25.5 & 24.6 & 39.9 & 38.5 & 8.9 & 8.4 & 25.8 & 28.6 \\
\hline 1975 & & 22.9 & & 36.7 & & 8.0 & & 32.4 \\
\hline 1976 & 22.5 & 22.7 & 37.0 & 37.0 & 8.2 & 8.3 & 32.3 & 32.0 \\
\hline 1977 & 23.1 & 23.2 & 36.9 & 37.0 & 8.5 & 8.4 & 31.6 & 31.5 \\
\hline 1978 & & 23.7 & & 36.8 & & 8.9 & & 30.6 \\
\hline 1979 & & 23.7 & & 37.1 & & 9.0 & & 30.3 \\
\hline 1980 & & 23.0 & & 37.6 & & 9.1 & & 30.3 \\
\hline 1981 & & 21.7 & & 38.5 & & 9.6 & & 30.2 \\
\hline 1982 & & 19.9 & & 39.4 & & 10.0 & & 30.8 \\
\hline 1983 & & 19.4 & & 39.5 & & 10.0 & & 31.0 \\
\hline 1984 & & 19.3 & & 40.6 & & 10.0 & & 30.1 \\
\hline 1985 & & 19.6 & & 41.0 & & 10.6 & & 28.9 \\
\hline 1986 & & 19.8 & & 41.6 & & 10.2 & & 28.4 \\
\hline 1987 & & 20.2 & & 41.9 & & 9.5 & & 28.4 \\
\hline 1988 & & 20.4 & & 42.2 & & 9.5 & & 27.8 \\
\hline
\end{tabular}

\footnotetext{
Source: Authors' computations from:

A) National Science Foundation, Graduate Student Support and Manpower Resources in Graduate Science Education, Fall 1965 and Fall 1966 (figure 9), Fall 1969 (table C10a), Fall 1970 (table C81), Fall 1971 (table C9); National Science Foundation, Graduate Science Education: Student Support and Postdoctorals, Fall 1972 (table C14); National Science Foundation, Graduate Science Education: Student Support and Postdoctorals, Detailed Statistical Tables, Fall 1974 (table B13), Fall 1975 (p. 11), Fall 1976 (table B10), Fall 1977 (table B10).

B) National Science Foundation, Academic Science/Engineering: Graduate Enrollment and Support, Fall 1988 (table C17), Fall 1981 (table C14).
}

been a clear upward trend. The number of students on federal support rose steadily between 1982 and 1988 and the 1988 level of 54,852 was over 16 percent higher than the 1982 level of 47,206. However, the total number of FTSEG enrolled in doctorate-granting institutions increased throughout the period, rising from about 195,500 in 1975 to almost 268,400 in 1988 . As a result, as table 1 indicates, the share of FTSEG in doctorate-granting institutions whose major source of financial support came from the federal government, fell from over $40 \%$ in 1966 to slightly over $19 \%$ in 1984. Between 1984 and 1988, as the number of FTSEG with federal support increased, the share with federal support increased slightly to $20.4 \%$. However, this is still well below the shares experienced in the late 1960s and early 1970s.

Table 1 also reports information on the percentages of FTSEG whose major sources of support came from "institutional" funds, "other outside" funds, and "self-support". In these data, "institutional funds" are defined to include funds from state governments administered by the insti- tutions, "other outside" funds include funds derived from foundations and corporations, as well as from foreign sources, while "self-support" includes loans, family support, and earnings from outside the university.

Quite strikingly, the fall from 1974 to 1988 in the percentage of FTSEG whose major source of support was the federal government from 24.6 to 20.4 was substantially offset by the increase in the percentage of FTSEG whose major source of support was institutional. As noted above, while this suggests that changes in federal support for graduate students may induce institutions to alter their own support levels, causation should not be inferred from these aggregate time-series data. ${ }^{8}$

\footnotetext{
${ }^{8}$ We must also caution that these data refer to students' major sources of support. So, for example, suppose a student who was initially receiving a $\$ 15,000$ tuition waiver from an institution subsequently received a supplementary $\$ 16,000$ fellowship stipend from the federal government. The student's reported major source of support would shift from the institution to the federal government. However, no reduction in institutional support would have occurred. Thus, the use of these "major source" of support data may overstate the extent of substitution of external for institutional funds.
} 


\section{Institutionally Based Analyses}

Consider the following simple equation that seeks to explain the number of FTSEG in institution $j$ in academic year $t$ supported by institutional funds $\left(I_{j t}\right)$. This equation can be motivated by a simple utility maximizing model of university behavior discussed in an appendix available upon request from the authors. ${ }^{9}$

$$
\begin{aligned}
I_{j t}= & a_{0}+a_{1} X_{j t}+a_{2} F_{j t}+a_{3} A_{j t} \\
& +v_{j t}+\epsilon_{j t} .
\end{aligned}
$$

Here $X_{j t}$ is the number of undergraduate students that the institution expects to be enrolled in science and engineering courses during the academic year, $F_{j t}$ is the number of science and engineering faculty employed by the institution in the academic year, $A_{j t}$ is the number of FTSEG in the institution supported by federal government and other external funds in the academic year, $v_{j t}$ is an institution-specific error term, and $\epsilon_{j t}$ is a random error term.

Presumably an increase in undergraduate student enrollments will increase the institution's demand for teaching assistants, so $a_{1}$ is expected to be positive. While an increase in science and engineering faculty size will similarly increase the institution's demand for graduate research assistants, holding undergraduate enrollments constant, it might decrease the institution's demand for teaching assistants. Thus, the sign of $a_{2}$ is a priori indeterminate.

The key variable in the model is the number of FTSEG supported on external funds. At one extreme, if the number of students the institution

\footnotetext{
Alternatively, suppose some of an institution's top students, who would have received institutional fellowships, get external fellowships instead. Suppose the university uses some (but not all) of the released institutional funds to provide lower-priced teaching assistantships for an equal number of other students, who otherwise would have to pay for themselves. In this case, there would be no reduction in the number of students being supported by institutional funds, but the number of dollars spent by the institution on graduate student support would have declined. Thus, our data would understate the extent of substitution.

The reader should keep these examples in mind when drawing conclusions from the econometric models presented below. Unfortunately data are not collected by department on the variety of sources from which a student receives any. support nor on the dollar amount of each type of support.

${ }^{y}$ See Garvin (1980) and James (1990) for more extensive discussions of utility maximizing models of university behavior.
}

supports is independent of the number that federal government and other external sources support, no displacement takes place and $a_{3}$ will be zero. In contrast, if the institution reduces the number of students it supports by exactly the number that the federal government and other external sources support, displacement will be complete and $a_{3}$ will equal minus one. Values of $a_{3}$ between zero and minus one indicate partial substitution of external for institution funds.

In theory, equation (1) can be estimated using a single year's data for a cross-section of doctorate-producing universities. However, the institution-specific error term presents a problem. Surely there are many other variables besides an institution's undergraduate enrollments and its faculty size that should affect its willingness to finance graduate students out of its own internal funds. Omission of these variables, which are captured by the institution-specific error term, may lead to biased coefficient estimates.

For example, suppose institutions that place a high value on graduate education and research simultaneously support above average (given their size) numbers of graduate students and hire first-rate faculty, who succeed in attracting above-average levels of support for graduate students from federal government and other external research grants. In the context of equation (1), this can be interpreted as high values for the institution-specific error term $\left(v_{j t}\right)$ simultaneously causing the numbers of FTSEG supported by external $\left(A_{j t}\right)$ and institutional $\left(I_{j t}\right)$ funds to be high. Thus, a spurious positive correlation will arise between the numbers of FTSEG supported by institutional and external funds and, if we ignore the institutional-specific error term, our estimate of $a_{3}$ will likely be biased.

One way around the problem is to try to make the institution-specific error term "observable" by including other variables with which it is likely to be correlated in the analyses (e.g., prestige measures of science and engineering fields in the institution). While we pursue such a strategy below, here we adopt a more parsimonious approach.

If one is willing to treat the institutional-specific error term as fixed over time $\left(v_{i t}=v_{i}\right)$ and one can obtain data for two or more time periods, then one can write equation (1) for each two adjacent periods ( $t$ and $t-1$ ), and take first 
Table 2.-Determinants of Institutional Support for Full-Time Science and Engineering Graduate Students in Research and Doctorate Universities, Fall 1979 to Fall 1984: FiXed EfFects Model (absolute value $t$-statistic)

\begin{tabular}{|c|c|c|c|c|c|c|c|c|}
\hline & \multicolumn{8}{|c|}{ ITOT } \\
\hline & (1a) & $(2 a)$ & (3a) & $(4 a)$ & (1b) & (2b) & (3b) & (4b) \\
\hline$T D$ & $.111(5.9)$ & $.109(5.9)$ & $.106(5.5)$ & $.101(5.3)$ & $.055(3.1)$ & $.052(3.0)$ & $.046(2.6)$ & $.041(2.3)$ \\
\hline FTE & $.148(8.6)$ & $.148(8.6)$ & $.122(7.0)$ & $.124(7.2)$ & $.085(5.2)$ & $.085(5.2)$ & $.055(3.3)$ & $.055(3.4)$ \\
\hline ATOT & $-.182(5.1)$ & & $-.023(0.5)$ & $-.061(1.5)$ & $-.146(4.4)$ & & $.013(0.3)$ & $-.019(0.5)$ \\
\hline ATOTI & & $-.162(4.4)$ & & & & $-.126(3.7)$ & & \\
\hline ATOTD & & $-.147(3.8)$ & & & & $-.111(3.1)$ & & \\
\hline ATOT1 & & & $-.728(6.1)$ & & & & $-.715(6.6)$ & \\
\hline ATOT 2 & & & & $-2.171(8.1)$ & & & & $-2.211(9.2)$ \\
\hline Year Dummies & & & & & & & & \\
\hline Included & no & no & no & no & yes & yes & yes & yes \\
\hline $\bar{R}^{\overline{2}}$ & .984 &.$\overline{984}$ & .984 &.$\overline{98}$ &.$\overline{98} \overline{6}$ &.$\overline{98} \overline{6}$ &.$\overline{98} \overline{7}$ & .987 \\
\hline $\mathrm{FICE} / \mathrm{DOF}^{\mathrm{a}}$ & $204 / 999$ & $204 / 998$ & $176 / 867$ & $176 / 867$ & $204 / 994$ & $204 / 993$ & $176 / 862$ & $176 / 862$ \\
\hline
\end{tabular}

(1) National Science Foundation, Survey of Graduate Science and Engineering Students and Postdoctorates: Fall 19xx (ITOT, ATOT).

(2) National Science Foundation, Survey of Scientific and Engineering Personnel Employed at Universities and Colleges: January 19xx (FTE).

(3) National Center for Education Statistics, Higher Educational General Information Survey (HEGIS): Academic Year 19xx (TD).

(4) Lyle V. Jones, Gardner Lindzey and Porter E. Coggeshall, eds., An Assessment of Research/Doctorate Programs in the United States (Washington, DC: National Academy Press, 1982) (ATOT1, ATOT2).

(1), (2), (3) and (4) are all available as part of the National Science Foundation's Computer Aided Science Policy Analysis and Research Database System (CASPAR). However, ITOT is not reported in CASPAR and the underlying data tapes must be used to obtain this variable.

Notes:

ITOT $=$ number of full-time science and engineering graduate students (FTSEG) supported by institutional and state funds on fellowships, traineeships, research assistantships, teaching assistantships or other types (primarily tuition waivers) of support in the fall of year $t$.

$T D=$ total bachelors' degrees in science and engineering granted by the institution in academic year $t+1$.

$F T E=$ total full-time scientific and engineering personnel employed by the institution in January of year $t+1$

$A T O T=$ number of FTSEG supported by federal government, other United States external (primarily corporate and nonprofit), and foreign funds in the fall of year $t$.

$A T O T I=A T O T$ if $A T O T \geq A T O T(-1), 0$ otherwise.

$A T O T D=A T O T$ if $A T O T<A T O T(-1), 0$ otherwise.

$A T O T 1=A T O T$ times the fraction of the institution's graduate programs that were rated at least one standard deviation above the rating of the mean program in their field in the 1982 National Research Council Doctorate Program ratings.

$A T O T 2=A T O T$ times the fraction of the institution's graduate programs that were rated at least two standard deviations above the rating of the mean program in their field in the 1982 ratings.

${ }^{a}$ FICE number of institutional dummy variables included in the analysis. DOF number of degrees of freedom.

differences to obtain

$$
\begin{aligned}
I_{j t}-I_{j t-1} & \\
= & a_{1}\left(X_{j t}-X_{j t-1}\right) \\
& +a_{2}\left(F_{j t}-F_{j t-1}\right)+a_{3}\left(A_{j t}-A_{j t-1}\right) \\
& +\left(\epsilon_{j t}-\epsilon_{j t-1}\right) .
\end{aligned}
$$

Estimation of (2), in which all variables are expressed as changes, will yield unbiased estimates of the parameter of interest, $a_{3}$, because the unobserved fixed effect has been eliminated from the model. Alternatively, one can obtain unbiased estimates by estimating an augmented version of the original model that includes institutionspecific intercept terms.

Table 2 presents estimates that use the latter approach and data from 200 doctorate producing universities on the number of FTSEG supported on institutional funds for each academic year between the Fall of 1979 and the Fall of $1984 .{ }^{10}$

\footnotetext{
${ }^{10}$ One can also formally test if the fixed effects model is appropriate by shifting $I_{j t-1}$ to the right-hand side of (2) and estimating a variant of the resulting equation that allows the coefficients of the contemporaneous and lagged value for each explanatory variable to differ in magnitude (as well as sign) and the coefficient of $I_{j t-1}$ to differ from unity. (Since $I_{j t-1}$ is correlated with $\epsilon_{j t-1}$, an instrument must be used for $I_{j t-1}$ and this instrument is obtained from a regression of $I_{j t-1}$ on $I_{j t-2}$ and the values from period $t-1$ of the other explanatory variables in the model.) When models were estimated that correspond to those found in columns (1a), (2a), (3a), and (4a) of table 2 , formal $F$ tests indicated that one can not reject the joint hypotheses that the coefficients of the contemporaneous and lagged value for each explanatory variable are equal and opposite in sign and that the coefficient of $I_{t j-1}$ is unity. That is, one can not reject the hypothesis that the fixed effects model is appropriate.

The importance of controlling for the fixed effects should be emphasized. When equation (1) was estimated in level form using the pooled data set, but ignoring the institution specific error term, the coefficient of the number of students supported on external funds switched signs, had a magnitude of about 0.3 , and was statistically significantly different from zero. The coefficients of the other explanatory variables remained roughly the same as in the fixed effects specification.
} 
The number of FTSEG supported on external funds in the Fall of each year $(A T O T)$ is defined as the sum of the numbers supported on federal government funds, on foreign funds, and on other United States (primarily corporate and nonprofit organization) funds. Support is defined here to include fellowships, traineeships, research assistantships (including those on externally funded research grants to faculty), teaching assistantships, and other types (primarily tuition waivers). These data come from the annual National Science Foundation Survey of Graduate Science and Engineering Students and Postdoctorates.

Data on enrollments in undergraduate science and engineering courses by institution are not available. What is available from the annual $\mathrm{Na}$ tional Center for Education Statistics Higher Educational General Information Survey is the total number of bachelors' degrees awarded in science and engineering fields by an institution in each academic year. ${ }^{11}$ While there is not necessarily a one-to-one relationship between changes in course enrollments and changes in graduating majors, the latter is the best proxy available for the former. Changes in degrees granted may well also lag changes in undergraduate enrollments. Preliminary analyses suggested that bachelors' degrees granted in science and engineering in the next academic year (TD) is a better predictor of institutional funding for graduate students in the current year than degrees granted in the current year and the former variable is used throughout the paper (Ehrenberg, Rees, and Brewer, 1992).

Finally, no data exist by institution on the number of faculty employed in science and engineering fields. However, from 1973 to 1985 the National Science Foundation's Survey of Scientific and Engineering Personnel Employed at Universities and Colleges collected information from doctorate granting institutions in January of each year on the total number of full-time scientists and engineers employed. ${ }^{12}$ These "headcounts" are not restricted to faculty, nor even to doctorates, but probably provide a reasonable approxi-

\footnotetext{
${ }^{11}$ In recent years the scope of the HEGIS survey has been expanded and it is now called the Integrated Postsecondary Education Data System (IPEDS).

${ }^{12}$ The cessation of this survey in January of 1985 precludes us from using more recent data on institutional and external support for graduate students in our analyses.
}

mation to the scale of research and teaching activity in science and engineering fields in the institution. Restricting the "headcount" to fulltime employees assures that graduate assistants are not included in the total. While it is again not a priori obvious whether the best predictor of the demand for research and teaching assistants in the Fall of a year, would be the number of full-time scientists and engineers employed in the institution in January of that year (the previous academic year) or in January of the next year (the current academic year), the latter proved to be more important in preliminary analyses and it (FTE) is used throughout the paper (Ehrenberg, Rees, and Brewer, 1992).

The results reported in columns (1a) through (4a) of table 2 suggest that changes in external support levels for FTSEG do influence institutional support levels. ${ }^{13}$ The simplest specification (col. 1a), suggests that for every 100 additional students supported by external funds, institutions reduced the number supported by institutional funds by about 18 . Whether the money saved was used to support graduate students in other nonscience/nonengineering fields, or for other purposes, can not be determined from these data.

Does this substitution of external for internal funds occur when external support is contracting as well as when it is expanding? The estimates reported in column (2a) allow the effects of changes in external support levels to differ between situations when external support is increasing (ATOTI) and when it is decreasing (ATOTD). The estimated effects are roughly equal suggesting that institutional responses to positive and negative changes in external funding are symmetric.

To say that substitution occurs is not to say that it occurs equally at all institutions. One way to stratify institutions is to rank them by the proportion of their doctorate programs that were rated at least one (or two) standard deviations above the rating of the mean program in their respective field in the 1982 National Research Council assessment of doctorate programs (Jones,

\footnotetext{
${ }^{13}$ The high $R^{2}$ in table 2 (and table 4 that follows) are due to the presence of the institution specific intercept terms in the level form of the model that was estimated. When the model was estimated in first difference form (equation 2) the same coefficients are obtained but the $R^{2}$ falls to roughly 0.05 .
} 
Lindzey, and Coggeshall, 1982). The models estimated in columns (3a) and (4a) include interactions of these proportions with ATOT (ATOT1 and $A T O T 2$, respectively). ${ }^{14}$ The coefficients of ATOT itself become statistically insignificant in these models, while the interaction terms are negative and significant, ${ }^{15}$ This suggests that the substitution of external for internal funds occurs primarily at institutions with highly rated programs; these tend to be the larger Research I (Carnegie category) institutions. Institutions with lesser rated programs apparently treat changes in external funding in a different manner; these institutions allow programs to "keep" all increases to help them improve, but in return make programs bear the full cost of all decreases in external funding.

Finally, columns (1b) through (4b) replicate the models previously estimated, adding to each a set of year dummy variables. To the extent that the latter variables capture the effects of nationwide changes in external support for FTSEGs that affect many institutions (for example, changes in the number of federal traineeships available), the estimated ATOT coefficients in these latter specifications may reflect primarily institutional responses to changes in the share of a given level of external funding that programs receive. On balance, the estimated responses are only slightly smaller than those found in the earlier specification, which suggests that institutional responses to change in external support for FTSEG are only slightly larger when the change is due to a change in national policy faced by all institutions, than when the change is due to a program's winning (or losing) a greater share of a given

\footnotetext{
${ }^{14}$ Only data from 177 institutions appear in these analyses because smaller programs were not ranked.

${ }^{15}$ The mean proportions of fields in an institution ranked one and two standard deviations above their respective field means were 0.11 and 0.02 , respectively, in this sample, so that on average the extent of substitution of external for internal support remains small. The "best" institution had all of its programs ranked at least one standard deviation and $80 \%$ ranked at least two standard deviations above the mean. The implied extent of substitution for this one institution was -0.751 (col. 3a) and -1.798 (col. 4a). The magnitude of the latter number (greater than one in absolute value) suggests that a nonlinear functional form is more appropriate here. In fact, for the specification in column $4 \mathrm{a}$, any institution that had $43 \%$ or more of its programs rated at least two standard deviations above the mean, would have an implied extent of substitution of greater than one. Six institutions fell in this group.
}

number of externally supported positions that are available nationwide. ${ }^{16}$

The results reported in table 2 assume instantaneous adjustment of the number of FTSEG students supported on institutional funds to annual changes in the number of FTSEG students supported on external funds, the number of degrees granted, and faculty size. Generalizing the model to capture the dynamics of the external support/institutional support interrelationship can proceed along at least two different lines. ${ }^{17}$

First, one can allow changes in external support levels in one year to affect the intertemporal allocation of institutional funds to support FTSEG. ${ }^{18}$ For example, the provision of external fellowships to support first-year entering graduate students in a field in year $t$ might induce an institution to reduce its internal support for entering students in the field in year $t$. However, to the extent that substitution was not one-for-one, the size of its entering class will have increased and thus the number of advanced FTSEG who need support will increase in subsequent years. To the extent that an institution uses some, or all, of the "saved" internal funds in year $t$ to support an increased number of FTSEG in subsequent years, focusing on contemporaneous responses, as we have done, will overstate the extent of substitution of external for institutional funds. A similar result would occur if institutions that previously provided support to students for four years used some of the saved internal funds in year $t$ to provide fifth year support in year $t+4$ for some of the new students who entered in year $t$.

One way to test such a hypothesis is to reestimate equation (1), adding as additional explanatory variables lagged values of external support for graduate students. The estimated coefficients

\footnotetext{
${ }^{16}$ All of the analyses presented in table 1 assume that the effects of changes in the various sources of external support (federal, foreign, and other United States (primarily corporate and foundation)) on the number of FTSEG supported by institutional funds are the same. Preliminary analyses that used data only for two years suggest that this assumption is warranted. See Ehrenberg, Rees, and Brewer (1992), table 5.

${ }^{17} \mathrm{~A}$ third line of approach is to postulate that since commitments to support graduate students are often made, at least implicitly, for more than one year at a time, that considerable inertia is built into the process and thus that substitution of external for internal funds occurs only with a lag. However, when a simple partial adjustment model was estimated, it implied that full adjustment did occur each year (Ehrenberg, Rees, and Brewer, 1992).

${ }^{18}$ We owe this hypothesis to Robert Hauser.
} 
Table 3.-Determinants of Institutional Support for Full-Time Science and EngineERing Students in Research and Doctorate Universities, Fall 1979 to Fall 1984: Selected Coefficients from Alternative SPECIFICATIONS OF FiXed EFFECTS MODELS

(absolute value $t$-statistics)

\begin{tabular}{|c|c|c|c|c|c|c|c|c|}
\hline \multicolumn{9}{|c|}{ A) Intertemporal Response Models ${ }^{a}$} \\
\hline & \multicolumn{4}{|c|}{ Year Dummies Excluded } & \multicolumn{4}{|c|}{ Year Dummies Included } \\
\hline & $(1 \mathrm{x})$ & $(2 \mathrm{x})$ & $(3 x)$ & $(4 \mathrm{x})$ & (1I) & (2I) & (3I) & (4I) \\
\hline ATOT & $-.213(5.6)$ & $-.204(5.3)$ & $-.198(5.2)$ & $-.178(4.6)$ & $-.181(5.1)$ & $-.173(4.8)$ & $-.169(4.8)$ & $-.181(4.5)$ \\
\hline $\operatorname{ATOT}(-1)$ & $.081(2.3)$ & $.033(0.9)$ & $.039(1.0)$ & $.039(1.0)$ & $.092(2.8)$ & $.045(1.3)$ & $.049(1.4)$ & $.049(1.4)$ \\
\hline $\operatorname{ATOT}(-2)$ & & $.107(3.0)$ & $.036(0.9)$ & $.048(1.2)$ & & $.105(3.1)$ & $.060(1.6)$ & $.065(1.8)$ \\
\hline $\operatorname{ATOT}(-3)$ & & & $.165(4.6)$ & $.101(2.6)$ & & & $.107(3.2)$ & $.077(2.1)$ \\
\hline $\operatorname{ATOT}(-4)$ & & & & $.140(1.0)$ & & & & $.068(2.0)$ \\
\hline
\end{tabular}

also included in the models were TD2 and FTE2.

B) Expected vs. Unexpected Change Models ${ }^{\mathrm{a}}$

\begin{tabular}{|c|c|c|c|c|c|c|c|c|}
\hline & \multicolumn{4}{|c|}{ Year Dummies Excluded } & \multicolumn{4}{|c|}{ Year Dummies Included } \\
\hline & $(1 \mathrm{x})$ & $(2 x)$ & $(3 x)$ & $(4 \mathrm{x})$ & (1I) & (2I) & (3I) & (4I) \\
\hline ATOTE & $-.132(3.1)$ & $-.072(1.5)$ & $.019(0.4)$ & $.124(2.1)$ & $-.089(2.3)$ & $-.029(0.6)$ & $.036(0.7)$ & $.095(1.8)$ \\
\hline ATOTU & $-.213(5.5)$ & $-.215(5.8)$ & $-.217(5.9)$ & $-.206(5.7)$ & $-.181(5.0)$ & $-.182(5.2)$ & $-.180(5.2)$ & $-.168(5.0)$ \\
\hline
\end{tabular}

ATOTE $=A T O T(-1)$ in columns (1)

$=(A T O T(-1)+A T O T(-2)) / 2$ in columns $(2)$

$=(\operatorname{ATOT}(-1)+\operatorname{ATOT}(-2)+A T O T(-3)) / 3$ in columns $(3)$

$=(A T O T(-1)+A T O T(-2)+A T O T(-3)+A T O T(-4)) / 4$ in columns $(4)$

$A T O T U=A T O T-A T O T E$ in each column

and

$A T O T=$ number of FTSEG in the institution supported by external funds

$A T O T E=$ number supported by external funds that is expected

$A T O T U=$ number supported by external funds that is unexpected

See table 2 for data sources.

${ }^{2}$ Also included in the models were the total bachelor's degrees in science and engineering granted by the institution (TD) and the total full-time scientific and engineering personnel employed in the institution (FTE).

of the external support variables that one obtains when this is done are found in table $3 \mathrm{a}$; models with variables representing one, two, three, and four years of lagged external support for graduate students were estimated. ${ }^{19}$ Although the magnitude of the response of current internal support to lagged values of external support differs across model specification, it is clear that focusing on the contemporaneous relationships overstate the extent of substitution of external for internal funds. Increases in external support for FTSEG in a period are associated with increases in internal support in subsequent periods that at least partially offset the contemporaneous substitution. ${ }^{20}$

Second, one can permit institutions to react differently to change in external support levels that they perceive as being transitory than to

\footnotetext{
${ }^{19}$ Thus, the sample used now extends from 1975 to 1984 .

${ }^{20}$ Indeed, formal $F$ tests indicate that one can not reject at the 0.95 level the hypothesis that the sum of these effects is zero in 5 of the 8 specifications (columns $(2 x),(3 x),(2 I),(3 I)$, and (4I)).
}

changes that they perceive as being permanent. ${ }^{21}$ Transitory increases, which are not expected to recur in future years, are unlikely to lead to large reallocations of institutional funds. Institutions may treat such increases as windfalls and compensatingly temporarily reduce their own expenditures for graduate support. In contrast, permanent increases, which institutions may view as fundamentally altering their wealth levels, are likely to lead to larger institutional commitments to graduate education and thus to less substitution of external for institutional funds. To the extent that the variation in changes in external support levels across institutions during a two-year period reflect primarily transitory fluctuations, our estimates in table 2 may overstate the extent to which institutions would reduce their own internal support for FTSEG in response to an increase in external support that was perceived to be more permanent.

Simple tests of this proposition are found in table $3 b$ which presents estimates of coefficients

\footnotetext{
${ }^{21}$ We owe this point to Michael McPherson.
} 
of $A T O T$ from extended specifications of equation (1) in which ATOT is divided into an expected (ATOTE) and an unexpected (ATOTU) component. The expected component is naively defined as either a one, two, three, or four year average of lagged values of $A T O T$, while the unexpected component is defined as the difference between the actual and expected components of $A T O T$ in each specification. ${ }^{22}$ The coefficients that result do indeed suggest that substitution of external for internal support occurs primarily in response to unexpected changes in external support.

\section{Disaggregation by Field}

To conclude that, in the aggregate, when the number of FTSEG supported by external funds increased by 100 , institutions reduce the number of FTSEG they support out of institutional funds by about 18 , is not to say that the response will be the same across all fields. To address the latter issue requires that separate analyses be undertaken by field. In doing so, however, one should allow for the possible interdependence of internal support levels across fields. For example, an increase in the number of students supported on external funds in one field might induce an institution to reduce the number of students it supports out of institutional funds in that field and then use all, or part, of the savings to fund more graduate students out of internal funds in other fields.

One way to test whether such interdependencies exist is to estimate a system of equations of the form:

$$
\begin{array}{r}
I_{j k t}=a_{0 k}+a_{1 k} X_{j k t}+a_{2 k} F_{j k t}+a_{3 k} A_{j k t} \\
+a_{4 k} A_{j t}+v_{j k}+\epsilon_{j k t} \\
\quad k=1,2, \ldots, 7 .
\end{array}
$$

In the above equations, the subscript $k$ indexes the field of study and the seven broad science and engineering subfields for which data were collected are engineering, physical sciences, life sciences, social sciences, environmental sciences,

\footnotetext{
${ }^{22}$ It should be clear to the reader that the specifications estimated in columns (2), (3), and (4) of table $3 \mathrm{~b}$ are restricted versions of the specifications estimated in the analogous columns of table $3 \mathrm{a}$. In particular, in each case the restriction is that the coefficients of all of the lagged values of ATOT included in the specification are equal in magnitude. Formal $F$ tests of these restrictions indicate that they can be rejected at the 0.05 level in only one of the six cases (column $3 \mathrm{x}$ ).
}

psychology, and mathematical sciences. The appendix again provides a simple model that motivates this econometric specification.

The number of students in a field supported out of institutional funds $\left(I_{j k t}\right)$ is assumed to depend in this specification on both the number of students in the field supported by external funds $\left(A_{j k t}\right)$ and the number of students supported by external funds in the institution as a whole $\left(A_{j t}\right)$. Ceteris paribus, an increase of 100 in the number of students in field $k$ supported by external funds would lead to a change in the number of students in field $k$ supported by internal funds of $100\left(a_{3 k}+a_{4 k}\right)$. Similarly, an increase of 100 in the number of FTSEG students supported in the institution as a whole by external funds, with no increase in the number of students in field $k$ supported by external funds, would lead to a change in the number of students supported by internal funds in field $k$ of $100 a_{4 k}$. A positive estimate of $a_{4 k}$ thus indicates that part of any increase in external support for graduate students elsewhere in a university is implicitly used to support graduate students in field $k$.

Equations (3) were estimated in level form, including institution specific intercept terms to account for the fixed effects, and data from a sample of 117 institutions that reported data for all seven fields for two or more years during the Fall 1979 to Fall 1984 period. Estimates are reported in table 4 for specifications that included and excluded year dummy variables.

Focusing first on the field-specific external support variables ( $A T O T F)$, external support appears to partially substitute for internal support in at least five of the seven fields and this substitution is statistically significant, in four of the fields. The magnitude of this substitution is largest in the physical sciences (44\% to $59 \%$ depending upon the specification) and is also above $20 \%$ in the life sciences, environmental sciences, and psychology. Only for engineering (for one specification) is there any evidence that increases in external support appear to be associated with increases in internal support. ${ }^{23}$

\footnotetext{
${ }^{23}$ On average, about $25 \%$ of all externally supported FTSEG in the sample are in engineering. Fields such as engineering that bring in a large amount of external support for graduate students, as well as other external research funds, may be able to use this success in debates over the allocation of internal funds to expand their share of internal graduate student support funds.
} 
Table 4.-Determinants of Institutional Support for Full-Time Science and Engineering Graduate Students in Research and Doctorate Universities, Fall 1979 to Fall 1984: Fixed Effects Model, by Field

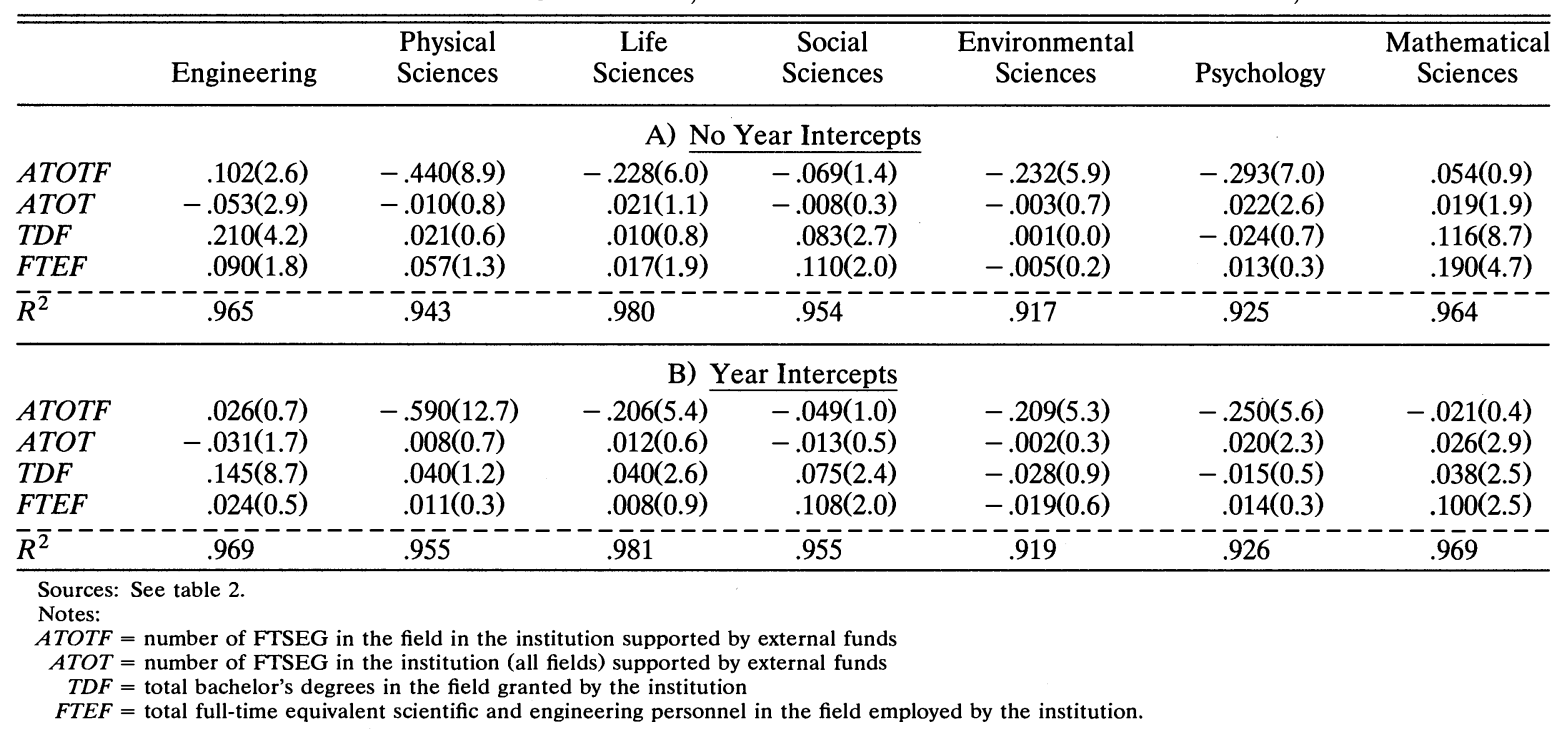

Of key interest are the estimated coefficients for the total external support variable $(A T O T)$. These estimates suggest that increases in the overall number of students supported by external funds in the science and engineering fields are used partially to subsidize graduate students in psychology and the mathematical sciences. Ceteris paribus, an increase of 100 in the number of FTSEG supported by external funds outside of these fields, leads to an increase in the number of students supported on institutional funds of roughly 2 each in both psychology and the mathematical sciences. As noted in earlier sections, whether a similar subsidization of graduate education in the humanities occurs can not be ascertained from these NSF data because the data lack information on graduate student support in humanities fields.

The estimates also suggest, however, that an increase in the overall number of students supported by external funds in the science and engineering fields, holding constant the number supported by external funds in engineering, is associated with a decrease in the number of students supported on internal funds in engineering. An increase in the number of nonengineering students supported on external funds of 100 is associated, ceteris paribus, with a decrease in the number of engineering students supported on internal funds of 3 to 5 . This may reflect the politics of the allocation of internal funds within institutions, with fields that are relatively successful in generating external funds (engineering) losing some of their "internal clout" when other fields' success increases.

\section{Concluding Remarks}

This paper has demonstrated that doctorateproducing universities respond to changes in the number of FTSEG supported on external funds by altering the number of FTSEG that they support on institutional funds. While institutional adjustment to changes in external support levels appear to be quite rapid, in the aggregate, the magnitude of these responses are quite small. An increase of 100 in the number of FTSEG supported by external funds is estimated to reduce the number supported on institutional funds by about 18. Since some of the institutional funds that are "saved" may be redirected to support graduate students in the humanities and other fields not represented in the data, the total affect of such a policy change on institutional support for graduate students is probably somewhat smaller.

This finding must be qualified for at least three reasons. First, while there is evidence that such institutional adjustments occur in periods of both increasing and decreasing external support, they 
tend to occur primarily in high quality programs which typically are found in Research I institutions. Second, long-run responses appear to be smaller than short-run responses; some of the institutional funds that are contemporaneously saved when external support increases are expended to support graduate students in subsequent years. Third, there is evidence that these institutional responses are larger in response to transitory, or unexpected, changes in external support, than they are in response to permanent, or expected, changes in external support. On balance these results suggest that, in the aggregate, increases in external support for FTSEG would lead to much smaller decreases in institutional support for graduate students.

Policymakers need be concerned, however, that the magnitudes of the responses appear to differ significantly across fields. There is also evidence that even within science and engineering there is some fungibility of external support across fields. In particular, institutional support for psychology and the mathematical sciences appears to increase somewhat in response to increases in external support to other science and engineering fields which permit institutions to reduce their own support to these other fields, while increases in external support to nonengineering fields appear to lead to decreases in institutional support for engineering.

In evaluating the importance of our findings, the reader should consider several points. First, as noted in footnote 8 , our analyses make use of data on number of students whose major sources of support come from institutional and external sources. We provide two reasons in the footnote why the use of such data might either overstate or understate the extent of substitution of external for institutional dollar funding of graduate students. Unfortunately, data on dollar amounts of institutional and external funding for graduate students are not available. Even if such data were available and one performed similar analyses to the ones we have performed using dollar funding levels, these analyses would still ignore the possibility that some of any "saved" institutional funds might be redirected by the institution to other uses that facilitate graduate students' degree progress. For example, institutions might use "saved" funds to provide graduate students with research support and/or with travel money for conferences. Hence, even if one had data on the dollar amounts of institutional and external funding of graduate students, using the methodology we have employed might lead one to overstate the extent of substitution of external for internal funding of graduate education more generally.

Second, FTSEG students who are supported from external funds typically receive different types of support than those who are supported from institutional funds. The former are more likely to receive fellowships and research assistantships, while the latter are more likely to receive teaching assistantships. ${ }^{24}$ Analyses of data from a single major doctorate producing institution on all graduate students who entered Ph.D. programs in four fields during a twenty-five year period suggests, other things held constant (including measured ability), that students who received fellowships and research assistantships had higher completion rates and shorter times-todegree than students who received teaching assistantships. ${ }^{25}$ Hence, even if increased external funding substituted for institutional funding on a dollar-for-dollar basis, if this substitution altered the distribution of types of funding towards more fellowships and research assistantships, it should still serve to increase the flow of new doctorates by increasing doctoral students' completion rates and decreasing their mean times-to-degree.

Finally, throughout the paper differences in institutional characteristics that might influence a university's desire and willingness to support graduate students are, for the most part, "buried" in the unobservable fixed effects. While in places we have included measures of graduate program quality in our analyses, and loosely linked our empirical research to simple utility maximizing models of university behavior, generalizations of our empirical models might productively be more explicitly tied to more general models of university utility maximization subject to budget con-

\footnotetext{
${ }^{24}$ For example, in the Fall of 1984 the proportions of FTSEG students whose major sources of support came from institutional and external funds, by type of support, in our sample were:

\begin{tabular}{|c|c|c|c|c|}
\hline & $\begin{array}{l}\text { Fellowship/ } \\
\text { Traineeship }\end{array}$ & $\begin{array}{c}\text { Research } \\
\text { Assistantship }\end{array}$ & $\begin{array}{c}\text { Teaching } \\
\text { Assistantship }\end{array}$ & Othe \\
\hline Institutional & .140 & .176 & .574 & .110 \\
\hline External & .279 & .515 & .018 & .188 \\
\hline
\end{tabular}
}


straints. ${ }^{26}$ One implication that would flow from such an approach is that institutional support for graduate students would depend on the "wealtl $\rightarrow$ levels of institutions. This suggests that measures of state budgetary tightness (in the public sector) or endowment strength (in the private sector) would be candidates to be added to future empirical models.

\section{REFERENCES}

Adams, Charles, et al., "A Pooled Time Series Analysis of the Job Creation Impact of Public Service Employment Grants to Large Cities," Journal of Human Resources 18 (Spring 1983), 283-294.

Borus, Michael, and Daniel Hamermesh, "Estimating Fiscal Substitution by Public Service Employment Programs," Journal of Human Resources 12 (Fall 1978); 561-565.

Bowen, William G., Graham Lord, and Julie Ann Sosa, "Measuring Time to the Doctorate," Proceedings of the National Academy of Sciences 88 (Feb. 1991), 713-717.

Bowen, William G., and Neil L. Rudenstine, In Pursuit of the Ph.D. (Princeton, NJ: Princeton University Press, 1992).

Bowen, William G., and Julie Ann Sosa, Prospects for Faculty in the Arts and Sciences (Princeton, NJ: Princeton University Press, 1989).

Breneman, David, "The Ph.D. Production Process" in Joseph Fromkin, et al., (eds.), Education As An Industry. (Cambridge, MA: Ballinger, 1976).

Ehrenberg, Ronald G., "Academic Labor Supply," Part II of Charles Clotfelter, Ronald Ehrenberg, Malcolm Getz,

${ }^{26}$ See, for example, Garvin (1980) and James (1990). and John Siegfried (eds.), Economic Challenges in Higher Education (Chicago, IL: University of Chicago Press, 1991)

"The Flow of New Doctorates," Journal of Economic Literature 30 (June 1992), 830-875.

Ehrenberg, Ronald G., and Richard P. Chaykowski, "On Estimating the Effects of Increased Aid to Education," in Richard B. Freeman and Casey Ichniowski (eds.), When Public Sector Workers Unionize (Chicago: University of Chicago Press, 1988)

Ehrenberg, Ronald G., and Panagiotis G. Mavros, "Do Doctoral Students' Financial Support Patterns Affect Their Times-to-Degree and Completion Probabilities?" (Cambridge, MA: National Bureau of Economic Research Working Paper No. 4070, 1992).

Ehrenberg, Ronald G., Daniel I. Rees, and Dominic J. Brewer, "How Would Universities Respond to Increased Federal Support for Graduate Students" in Charles Clotfelter and Michal Rothschild, (eds.), Studies of Supply and Demand in Higher Education (Chicago: University of Chicago Press, 1992).

Garvin David, The Economics of University Behavior (New York: Academic Press, 1980).

James, Estelle, "Decision Processes and Priorities in Higher Education" in Stephen Hoenack and Eileen Collins, The Economics of American Universities (Albany: SUNY Press, 1900).

Jones, Lyle V. Gardner Lindsey, and Porter E. Coggeshall (eds.), "An Assessment of Research-Doctorate Programs in the United States (Washington, D.C.: National Academy Press, 1982).

National Research Council, Summary Report 1988: Doctorate Recipients from United States Universities. Washington, DC: National Academy Press, 1989).

National Science Foundation, Academic Science/Engineering Graduate Enrollment and Support, Fall 1988 (Washington, D.C., 1990). 